\title{
Evaluation Index of School Sports Resources Based on Artificial Intelligence and Edge Computing
}

\author{
Long Hao and Li-Min Zhou \\ Institute of Physical Education and Training, Harbin Institute of Physical Education, Harbin 150006, Heilongjiang, China \\ Correspondence should be addressed to Li-Min Zhou; zhoulimin1968@163.com
}

Received 24 September 2021; Revised 10 November 2021; Accepted 16 November 2021; Published 13 January 2022

Academic Editor: Sang-Bing Tsai

Copyright ( $) 2022$ Long Hao and Li-Min Zhou. This is an open access article distributed under the Creative Commons Attribution License, which permits unrestricted use, distribution, and reproduction in any medium, provided the original work is properly cited.

\begin{abstract}
As the demand for education continues to increase, the relative lack of physical resources has become a bottleneck hindering the development of school physical education to a certain extent. This research mainly discusses the evaluation index system of school sports resources based on artificial intelligence and edge computing. Human resources, financial resources, and material resources in school sports resources are the three major resources in resource science. University sports stadium information publicity uses Internet technology to establish a sports information management platform and mobile Internet terminals to optimize university sports resources and stadium information management services. It uses artificial intelligence technology to improve venue information management. It establishes a comprehensive platform for venue management information, collects multidimensional information, provides information resources and accurate information push, and links venue information with public fitness needs. Using edge computing to realize nearby cloud processing of video data, reduce the phenomenon of black screen jams during live broadcast, improve data computing capabilities, and reduce users' dependence on the performance of terminal devices, build a smart sports resource platform, combine artificial intelligence (AI) to create smart communities, smart venues, and realize intelligent operations such as event service operations and safety prevention and control in important event venues. During the live broadcast of the student sports league, the nearby cloud processing of video data is realized in the form of edge computing, which improves the data computing ability and reduces the performance dependence on the user terminal equipment itself. In the academic survey of college physical education teachers, undergraduates accounted for $26.99 \%$, masters accounted for $60.3 \%$, and doctoral degrees accounted for $12.8 \%$. This research will help the reasonable allocation of school sports resources.
\end{abstract}

\section{Introduction}

Sports resources are an indispensable foundation and condition for Chinese citizens to exercise, strengthen their physique, and enrich their cultural life. However, because our country's productivity is not yet developed and sports resources are still in short supply, it cannot be accomplished overnight. We can only improve this temporary pattern of inequality in stages and steps.

This research aims to conduct in-depth research on the concepts, types, characteristics, and functions of school sports resources from the perspective of resource science and build a set of school sports resource evaluation systems on the basis of the research. The evaluation of the index system reveals urban and rural areas objective gaps in school sports resources, providing a realistic reference for the country to rationally allocate school sports resources at all levels and types.

The application of edge computing in emerging technology fields is becoming more and more common. Xu et al. believed that edge caches are vulnerable to cache pollution attacks (CPAttacks), leading to interruption of content delivery. Even according to the CPAttacks model, the cache status of edge devices is characterized by the two parameters of content request rate and cache loss rate. However, their research lacks the necessary data [1]. Luo et al. believed that vehicle edge computing (VEC) integrates mobile edge computing (MEC) into the vehicle network, which can provide more functions to execute resource-constrained applications and reduce the waiting time for connected 
vehicles. Even though they proposed a dual importance (DI) evaluation method to reflect the relationship between vehicle priority $(\mathrm{PoV})$ and content priority (PoC), their research method has certain flaws [2]. Liu et al. believed that, in recent years, with the explosive development of smart cities, green energy management systems have been extensively studied. By introducing Internet of Things (IoT) technology, smart cities can achieve energy management through ubiquitous monitoring and reliable communications. They focused on designing an IoT-based energy management system based on an edge computing infrastructure with deep reinforcement learning. First, they gave an overview of energy management based on the Internet of Things in smart cities. Then, they proposed a framework and software model of an IoT system based on edge computing. Although they proposed an effective energy dispatching scheme with deep reinforcement learning for the proposed framework, their research lacks a certain degree of innovation [3]. Cao et al. believed that, as a supplement to the traditional remote cloud center, the multiaccess edge computing (MEC) deployed in the vicinity of the mobile user terminal has been regarded as a promising technology for $5 \mathrm{G}$ heterogeneous networks. In order to adapt to the random and constantly changing environment, enhanced intelligence (AI) is introduced in MEC to make intelligent decisions. Although they also discussed some potential problems of AI in MEC for future work, their research is not accurate enough [4].

This research mainly discusses the evaluation index system of school sports resources based on artificial intelligence and edge computing. Human resources, financial resources, and material resources in school sports resources are the three major resources in resource science. University sports stadium information publicity uses Internet technology to establish a sports information management platform and mobile Internet terminals to optimize university sports resources and stadium information management services. It uses artificial intelligence technology to improve venue information management. It establishes a comprehensive platform for venue management information, collects multidimensional information, provides information resources and accurate information push, links venue information with public fitness needs, and uses edge computing to realize the nearby cloud processing of video data, reducing the jam and black screen phenomenon in the live broadcast process of the game. The phenomenon of black screen in the middle of the caton improves the data computing ability, reduces the dependence on the performance of the user terminal equipment itself, builds a smart sports resource platform, and combines artificial intelligence (AI) to create smart communities and smart stadiums, and realizes event services and operations in important competition venues, intelligent travel, safety prevention, control, and so on.

\section{School Sports Resource Evaluation Index System}

2.1. Artificial Intelligence. With the technological development of hardware and software equipment, the capabilities and superiority of artificial intelligence have rapidly penetrated all areas of life. The pattern recognition of artificial intelligence is the process by which a computer can recognize and process information from the outside world by simulating the human senses. In recent years, with the rapid development of digital information theory and computer technology, people continue to try to process natural information and convert it into digital signals and then realize the process of analyzing and processing digital signals through computer intelligence. The role of artificial intelligence in the course of teacher preparation is mainly reflected in providing teachers with data resources and creating virtual teaching environment models. The teacher's lesson preparation is to prepare the classroom, prepare the content, and, more importantly, prepare the students. Teachers can obtain students' learning data through intelligent teaching programs and software and intelligently generate academic analysis to help teachers understand students more comprehensively [5]. The results calculated by the average method $P(x, y)$ are basically relatively uniform [6]:

$$
P(x, y)=\frac{(R(x, y)+G(x, y)+B(x, y))}{3} .
$$

The sports resource $M(x, y)$ is averaged, and each element has a different weight $R$ [7]:

$$
M(x, y)=0.3 R(x, y)+0.59 G(x, y)+0.42 B(x, y) .
$$

The maximum output power $P_{R o}$ is usually equal to the external load of the internal resistance [8]:

$$
\begin{gathered}
P_{\max }=\left(\frac{V_{\text {in }}}{y i+y o}\right)^{2} \times y o, \\
\frac{d^{2} P_{R o}}{d R o^{2}}=2 V_{i n}^{2} \times \frac{R o-2 R i}{(R i+R o)^{4}} .
\end{gathered}
$$

2.2. Edge Computing. Mobile edge computing (MEC), as a key technology for the evolution of $4.5 \mathrm{G} / 5 \mathrm{G}$ network architecture, can meet the system's requirements for throughput, delay, network scalability, and intelligence. At present, most of the task migration problems are researched in the cloud computing environment and the mobile edge computing environment. In the migration process in the cloud computing environment, most of the hosts with intensive computing tasks are detected, and some or all of the tasks on them are migrated to physical servers with sufficient computing resources. The task offloading process performed in the mobile edge computing environment is mainly to migrate the terminal device to the edge server, so as to improve the performance of the terminal device and save energy consumption. In the current research, there are relatively few studies on task migration in edge computing platforms, and it is even rarer to consider whether computing tasks are migrated between cloud edges or between edges. At the same time, due to the mobility and uncertainty of terminal equipment in the edge computing environment, a large number of task migration processes will inevitably be carried out on the platform, and the corresponding network load pressure will also 
increase [9]. Define the underlying server network topology in the edge computing platform as an undirected weighted graph [10]:

$$
G^{S}=\left(N^{S}, E^{S}\right)
$$

The collection of servers in the platform is $N^{S}$ [11]:

$$
N^{S}=N^{r} \cup N^{e}
$$

The energy consumption, communication, and migration costs on edge computing platforms are often the smallest [12].

$$
C_{\min }=\alpha C_{e}+\beta C_{c}+C_{m}
$$

The comprehensive cost $C$ is mainly to evaluate the migration decision more comprehensively and comprehensively [13]. Energy consumption includes the energy consumption of starting physical nodes and the cost of computing tasks. The latter is linearly related to the processing power of the CPU. Because this part of the cost does not change with the migration of tasks in the system, the energy consumption part only considers the cost of starting physical nodes in the system. Therefore, the definition of energy consumption $U_{j}$ is as follows [14]:

$$
\begin{aligned}
& C_{1}=\sum_{j=0}^{|N-1|} e_{m} R E, \\
& E_{j}=\int\left(P_{i}(j)+P_{l}(j)+P_{k}(j)\right) \mathrm{d} t, \\
& U_{j}=\min \left\{\frac{\sum_{I} R(E)}{N_{1} C}, 1\right\} .
\end{aligned}
$$

Among them, $e_{m} \in(0,1)[15,16]$. Because task migration in the edge computing platform needs to be carried out in decentralized data centers, when tasks are transferred between different physical hosts, there are both memory data migration and storage data migration [17]. Therefore, the migration cost quantified by time is

$$
\begin{aligned}
& R=B \log _{2}(1+s), \\
& T=\frac{(M+C)}{R} D,
\end{aligned}
$$

where $R$ represents the channel capacity during the migration process and $B$ represents the network transmission bandwidth $[18,19]$.

2.3. Sports Resources. Nowadays, college sports resources are mainly manifested in the rich resources of venues and facilities and strong sports professional teachers and students. However, most of the sports resources of colleges and universities are used to develop education and scientific research, they have not assumed the function of serving the society, and the management system is lagging [20]. For this reason, the concept of sustainable development of college sports venues in the new era should be realized so that the limited sports venue resources can better meet the sports activities needs of teachers, students, and the majority of community residents and promote the healthy development of physical fitness [21]. Sports resources in colleges and universities involve a wide range of areas, which can be roughly summarized into three aspects: teacher and student resources, venue resources, and funding resources. With the in-depth development of the concept of national fitness, the publicity of sports fitness knowledge and scientific and technological services are also sports resources for colleges and universities to provide services to community residents. Among them, material resources refer to sports venues and equipment, and human resources refer to teachers and students majoring in physical education in colleges and universities, as well as teachers and students who are keen to serve mass sports $[22,23]$. The processing of sports resources is related to the corresponding coefficient value $\mu$ [24]:

$$
\begin{aligned}
\mu & =\sum_{i=0}^{k-1} \frac{i P_{0}}{\omega_{0}}+\frac{\mu(k)}{\omega(k)}, \\
\mu_{1} & =\sum_{i=k}^{M-1} \frac{o_{1}}{\omega_{1}}+\frac{\mu-\mu(k)}{1-\omega(k)}+\frac{\beta-\mu(k)}{\delta} .
\end{aligned}
$$

Although school sports information is not as broad as sports information, school sports information is a transit point for the acquisition of school sports information and the dissemination of sports information [23, 25]. When calculating sports resources, the overall information combined with local features can be obtained.

\section{School Sports Resource Evaluation Experiment}

3.1. School Sports Resource Indicators. Human resources, financial resources, and material resources in school sports resources are the three major resources in resource science. This study takes time resources as the first-level index of the school sports resource evaluation system. School sports human resources include physical education teachers, sports managers, and physical education assistants. Human resources in the school sports resource evaluation system are used as the first-level indicators; physical education teachers, sports managers, and physical education assistants are used as the second-level indicators for the evaluation of school sports human resources; the indicators for the evaluation of physical education teachers (third-level indicators) are mainly from: age, education, professional title, profession, workload, training, clothing equipment, monthly income, and teacherstudent ratio, 9 subindicators for evaluation. The evaluation index (three-level index) of school physical education managers and school physical education assistants is mainly evaluated from the four subindices of age, educational background, major, and professional title, which constitute the school physical human resource evaluation system.

Financial resources: government investment and social donations. Material resources: sports venues and sports 
equipment. Information resources: newspapers, magazines, books, and network resources. Time resources: physical education classes, sports competitions, and extracurricular activities.

\subsection{Optimization of Venue Information Publicity Services.} Venue information publicity services effectively improve residents' sports awareness and facilitate residents to obtain high-quality sports services, venue information publicity services, venue information publicity content, including physical exercise methods, sports policies and regulations, and the latest sports trends; venue information publicity forms, blackboard newspapers, publicity columns, and postpropaganda slogans; and venue information propaganda media, such as TV, the Internet, and magazines, in various forms to increase public fitness and sports awareness. University sports stadium information publicity uses Internet technology to establish a sports information management platform and mobile Internet terminals to optimize university sports resources and stadium information management services. It uses artificial intelligence technology to improve venue information management. It establishes a comprehensive platform for venue management information, collects multidimensional information, provides information resources and accurate information push, links venue information with public fitness needs, and uses edge computing to realize the nearby cloud processing of video data, reducing the jam and black screen phenomenon in the live broadcast process of the game. The phenomenon of a black screen in the middle of the freeze improves the data computing ability and reduces the performance dependence on the user terminal device itself. It promotes cooperation between management systems, dynamically updates monitoring in real time, completes realtime monitoring of venues and users, feeds back, improves work, and achieves professional and intelligent management. Information collection, information sharing, information push, opinion feedback and dynamic monitoring, and so forth are multifunctional and coordinated to form a complete information management system, building a $5 \mathrm{G}+$ smart sports resource platform. The $5 \mathrm{G}+$ smart sports resource platform mainly builds a $5 \mathrm{G}$ network environment for the stadiums and venues. With the help of virtualization, artificial intelligence, edge computing and other technologies, it creates a $5 \mathrm{G}$ smart application platform for the game, combining artificial intelligence (AI) to create smart communities and smart stadiums in important competition venues to realize the intelligentization of competition services, operation, and security prevention and control.

3.3. Internet + University Stadium Resources. With the application of Internet information technology in all aspects of life, APP applications such as Alipay, Didi, and WeChat provide convenience for people's lives. Through the use of Internet technology, the blind spots of the public fitness practitioners on the resources of the stadium are eliminated, the connection between the college stadiums and the public fitness practitioners has been strengthened, and a good communication platform has been established. Build an Internet + university stadium resource sharing information technology platform, which can be designed to include information, venue name, venue location, venue opening service time, charging standards, service items, and service personnel; it can be designed to include reservations, venue reservations, and appointment service coaches and can be designed to include sports information, push the latest service items, push tips on preventing sports injuries, push the methods and methods of correct physical exercise, and so on. Through the Internet technology, we will provide technological innovations to the stadiums of universities and colleges and return the resources of the stadiums to sports and to the people. The principle of smart event live broadcast is shown in Figure 1.

During the live broadcast of the student sports league, multiple live cameras are used for simultaneous video shooting. The multiple channels of video are combined by the live encoder and uploaded to the cloud computing cluster through RTMP. The production of $6 \mathrm{DOF}$ video is realized through the $3 \mathrm{D}$ reconstruction algorithm, and then the video is passed through RTMP upstream to the live broadcast center. When the user terminal chooses to enter 6 DOF video playback, the edge cloud finds the closest MEC edge computing node through the scheduling service, the user uploads the live or on-demand ID and user viewing angle to the MEC edge node, the MEC edge node pulls the corresponding 6DOF live HLS stream, download is realized, and after downloading and decoding, the video stream of the corresponding angle is calculated by the algorithm difference according to the user's incoming angle and sent to the end user through the $5 \mathrm{G}$ network. In the entire link, the $3 \mathrm{D}$ rendering and reconstruction of the video rely on the technical integration of the telecom edge cloud computing MEC and the cloud edge computing operating system, use edge computing to realize nearby cloud processing of video data, improve data computing capabilities, reduce the performance dependence on user terminal equipment itself, further optimize the network delay of user access, and more calmly deal with large traffic and high concurrency while reducing the center. In this way, it can better respond to the pressure of large broadband and lowlatency service requirements faced in large-scale Internet scenarios such as live events, variety shows, and online education.

\subsection{Introducing or Cultivating Professional Management} Talents for Sports Venues. The construction of a professional management team can not only meet the needs of university stadiums but also serve the society better, and it is also a talent foundation for the implementation of innovative operations, regularly conducting brainstorming among managers and exchanging and ing management experience. The training content covers stadium management, stadium operation, stadium maintenance, and construction of a professional management team. The introduction of professional management talents for sports venues plays a leading role in the management of college sports venues, 


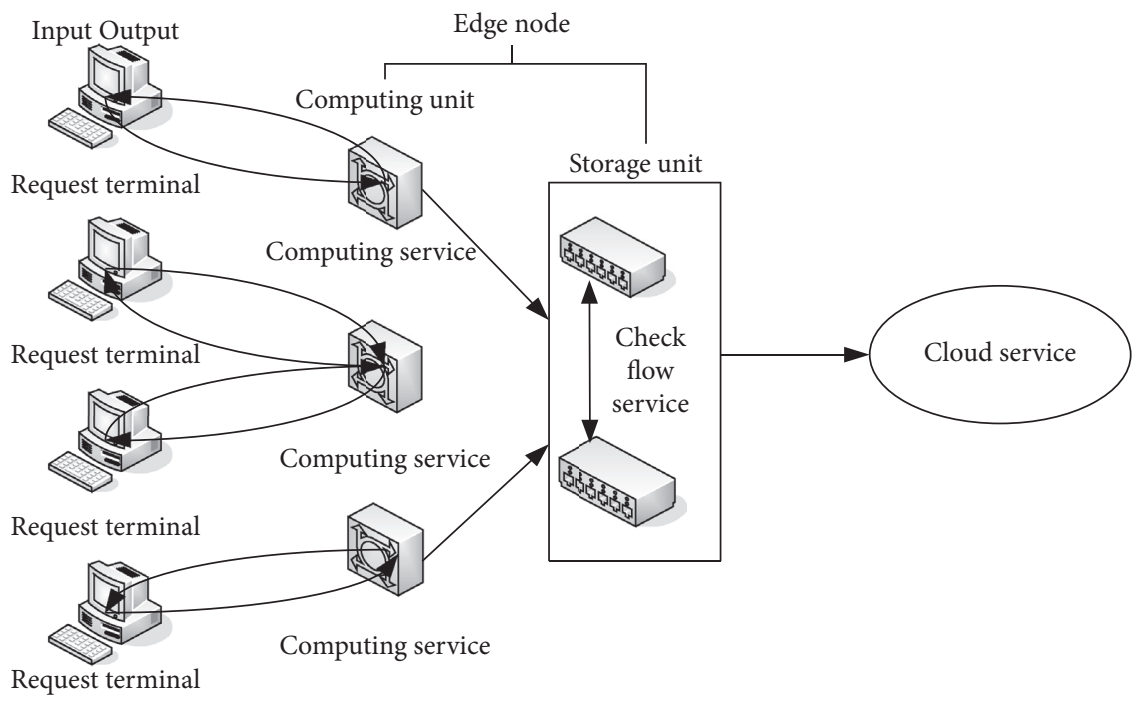

FIGURE 1: The principle of smart event live broadcast.

improves the rules and regulations of sports venues, establishes a professional sports venue management team, and improves the talent structure of the management team. Introducing or cultivating stadium management talents can effectively alleviate the shortage of stadium personnel and effectively improve the management problems of college stadiums.

\section{Results and Discussion}

Sports venues and equipment are symbols of colleges and universities' landmarks and functions. They are mainly used for daily teaching, competitive training, physical exercises for teachers and students, and important venues for extracurricular activities. Therefore, the implementation of the construction and standardization of sports venue resources in colleges and universities is conducive to not only promoting college sports but also improving the quality of scientific research and teaching training, providing a core foundation for "lifelong sports." The number of sports venues in province M has increased from 19277 to 40103, among which the number of college sports venues has increased from 776 to 2,143 . It can be seen that the construction of sports venues in province $\mathrm{M}$ has closely followed the national policy requirements for the development of healthy China. It not only provides convenient services in the teaching process of teachers and students but also provides potential new resources for national fitness. Information about sports venues and equipment is shown in Table 1.

The age structure of sports managers is shown in Figure 2. Judging from the distribution of the age structure of sports managers, whether it is a city or a township school, the age structure is more reasonable. The proportion of 50-59 years old and under 30 years old is small, mainly distributed in the two age groups 30-39 years old and $40-49$ years old; these two age groups are the ideal age for managers (1. Have rich experience, 2. The best age to do a career).
The part-time situation of school physical education teachers is shown in Table 2. During the investigation, it was found that the part-time school physical education teacher mainly assists the work of the Political and Education Office and participates in the management of students in the school. The part-time situation of urban middle school teachers is higher than that of township schools, and the workload of urban and rural teachers is unbalanced. It is necessary to improve the part-time situation of physical education teachers in urban schools so that they can devote themselves to their own work.

For colleges and universities, the age structure of teachers reflects the current education situation to a certain extent. Young teachers inject new vitality and new ideas into colleges and universities and stimulate students' interest in learning. Teachers with high teaching age have rich teaching knowledge and teaching training experience. The ability of scientific research and innovation can also provide young teachers with teaching training, scientific research, and other experience, providing a basis for high-quality teaching. The situation of physical education teachers of all age groups in 5 universities is as follows: about $11.7 \%$ under the age of 29 ; about $55.9 \%$ between 30 and 39 years; about $21.8 \%$ between 40 and 49 years; and 10.6\% 50 years and above. From the data, it can be seen that the distribution of the three stages of old, middle, and youth is relatively reasonable, with the largest number of people between the ages of 31 and 40 . From the perspective of physiology and psychology, this period belongs to the golden stage, which is full of energy and is more conducive to colleges and universities. The physical education practice activities provide impetus for the development of colleges and universities. The age distribution of physical education teachers is shown in Table 3 .

There are four types of teacher titles in colleges and universities: professors, associate professors, lecturers, and teaching assistants. The more the titles of the associate senior and above in colleges and universities, the higher the scientific research level and education quality of colleges and universities. Among the 5 universities surveyed, Table 3 
TABLE 1: Sports venues and equipment information.

\begin{tabular}{lc}
\hline Site & Quantity \\
\hline Athletic field & 11 \\
Basketball court & 58 \\
Volleyball court & 22 \\
Football field & 11 \\
Swimming pool & 4 \\
Bocce court & 8 \\
Table tennis table & 22 \\
Tennis court & 8 \\
Badminton court & 3 \\
Martial arts hall & 4 \\
Gymnastics equipment hall & 4 \\
Gym & 11 \\
\hline
\end{tabular}

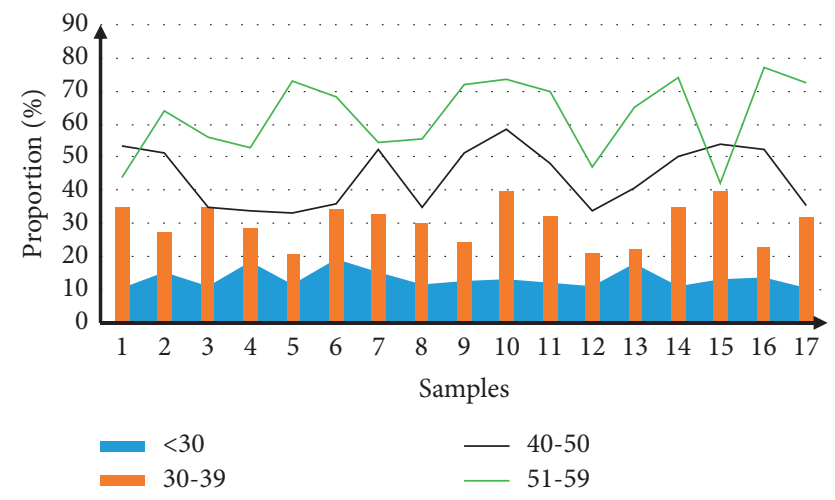

Figure 2: The age structure of sports managers.

TABle 2: Part-time jobs of school physical education teachers.

\begin{tabular}{lcc}
\hline Object & Part-time & Not part-time \\
\hline City school $(n=176)$ & $114(64.8)$ & $62(35.2)$ \\
Township school $(n=222)$ & $135(60.8)$ & $87(39.2)$ \\
\hline
\end{tabular}

TABLe 3: Age distribution of physical education teachers.

\begin{tabular}{lcc}
\hline Generation & Quantity & Percentage \\
\hline Under 29 & 68 & 11.7 \\
$30-39$ years old & 325 & 55.9 \\
$40-49$ years old & 127 & 21.8 \\
Over 50 years old & 62 & 10.6 \\
\hline
\end{tabular}

shows that the number of teaching assistants is 84 , accounting for approximately $14.4 \%$; the number of lecturers is 187 , accounting for approximately $32.1 \%$; the associate professor level is 234, accounting for approximately $40.2 \%$; professors are 77, accounting for about $13.3 \%$. Through the statistical analysis, in the 5 colleges and universities currently surveyed, the trend of professional titles of physical education teachers provides young teachers with a multidevelopment platform. The titles of various college teachers are shown in Figure 3.

The educational background of school physical education teachers is shown in Table 4. The educational level not only represents the level of a person's education and culture but also interprets the individual's knowledge, ability, and skill practice level. Therefore, the academic structure of physical education teachers in colleges and universities can indicate the ability of the school in teaching practice, competitive training, and scientific research results. As can be seen from Table 4, undergraduates accounted for $26.9 \%$, masters accounted for $60.3 \%$, and doctoral degrees accounted for $12.8 \%$. It can be seen from the data that the current overall level of physical education teachers in colleges and universities has reached a certain height, which can bring greater educational value to the teaching, training, and scientific research of colleges and universities and provide a driving force for the good development of colleges and universities.

The charging situation of the university sports resource field is shown in Figure 4. All sports resources in colleges and universities are not open to the outside world, which affects the sports of residents in surrounding communities to a certain extent; the resource venues for public welfare open services only account for $9.4 \%$, and paid services and some paid services account for $28.7 \%$ and $14.23 \%$, respectively. The venues for external services are mostly outdoor venues, such as table tennis, badminton courts, and venues for the three major sports. The management costs of these venues are relatively low, and the open objects are mainly for the teachers and students of the school and surrounding residents; most of the paid openings are indoors. Venue resources, such as swimming pools, ping-pong halls, gymnasiums, and tennis courts, are due to the special requirements of site materials, management personnel costs, and maintenance costs, so corresponding fees are charged to reduce the burden on the school.

Table 5 shows the form of external services of university sports venues. It can be seen from Table 5 that $60.3 \%$ of the resources provided by some college sports venues provide free services to the outside world, including outdoor track and field courts, basketball courts, ping-pong and badminton tennis courts, and gymnasiums. Through investigation, it is found that, under the premise of not affecting normal teaching and training, most of the outdoor venues in colleges and universities are open, providing free services to teachers, students, and surrounding residents. However, $39.7 \%$ of sports venues are paid services, basically indoors. The main reason for the fee is the daily cleaning of the venue and the repair and maintenance of the equipment. If all are open, the university will bear the relevant costs while taking the safety factor. For this reason, the university venues charge corresponding fees when serving residents to exercise. In the investigation, it was found that some venues undertook various forms of competitions during a certain idle time, and charged certain fees in accordance with the standards to pay for the management staff's labor costs and daily maintenance costs.

The opening hours of school sports resources are shown in Figure 5. Among them, 6-8 in the morning and 17-19 in the afternoon accounted for $27.2 \%$ and $24.6 \%$, respectively, 19-22 at night accounted for $29.8 \%$, and $12-14$ at noon accounted for about $18.4 \%$. Considering the normal teaching order, the opening time is basically open before and 


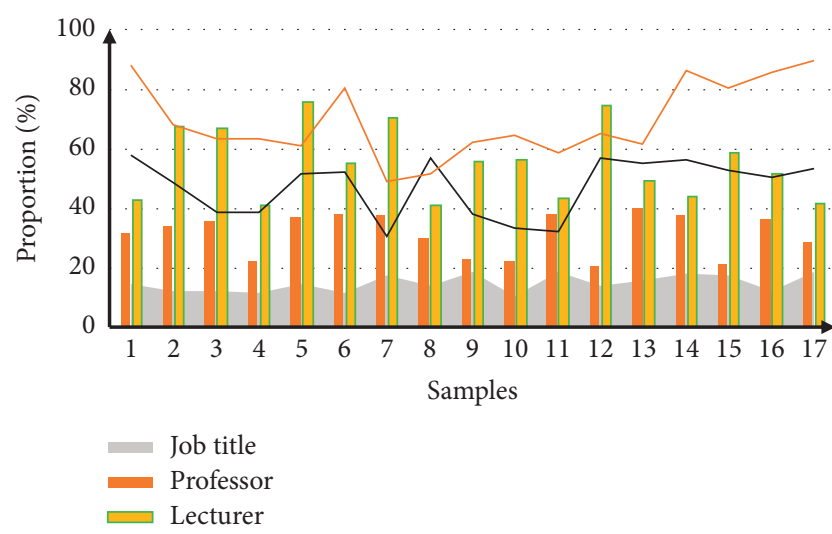

FIgURE 3: Various titles of teachers in colleges and universities.

TABLE 4: Educational qualifications of school physical education teachers.

\begin{tabular}{lcc}
\hline Education & Quantity & Percentage \\
\hline Ph.D. & 74 & 12.8 \\
Master's degree & 351 & 60.3 \\
Undergraduate & 157 & 26.9 \\
\hline
\end{tabular}

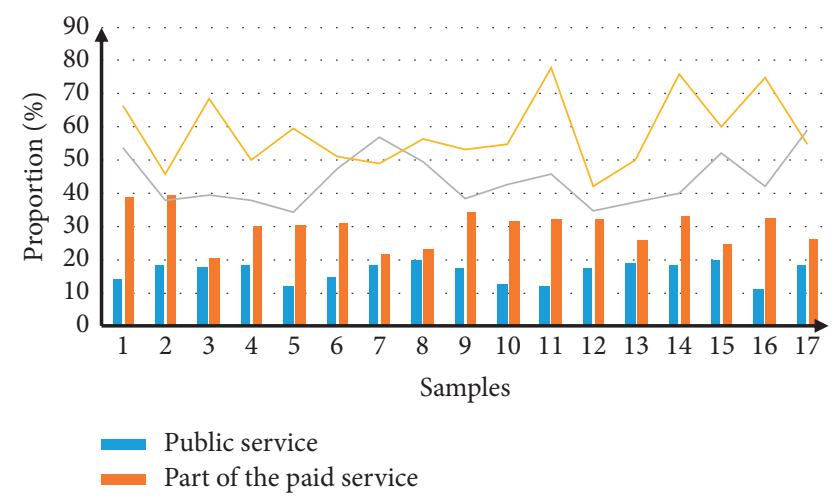

FIGURE 4: Fees for sports resource fields in colleges and universities.

TABLE 5: Forms of external service of university sports venues.

\begin{tabular}{lc}
\hline Free service venue & Quantity \\
\hline Outdoor track and field & 9 \\
Outdoor basketball court & 50 \\
Outdoor volleyball court & 16 \\
Outdoor table tennis table & 121 \\
Outdoor badminton court & 12 \\
Indoor basketball court & 7 \\
Indoor volleyball court & 5 \\
Indoor table tennis table & 66 \\
Indoor badminton court & 61 \\
Indoor tennis court & 8 \\
\hline
\end{tabular}

after class, but this also limits the time for residents to participate in exercise in colleges and universities to a certain extent, so that residents' sports are in a passive state. Overall analysis shows college sports resources provide certain services to the outside world, but how to improve reasonable

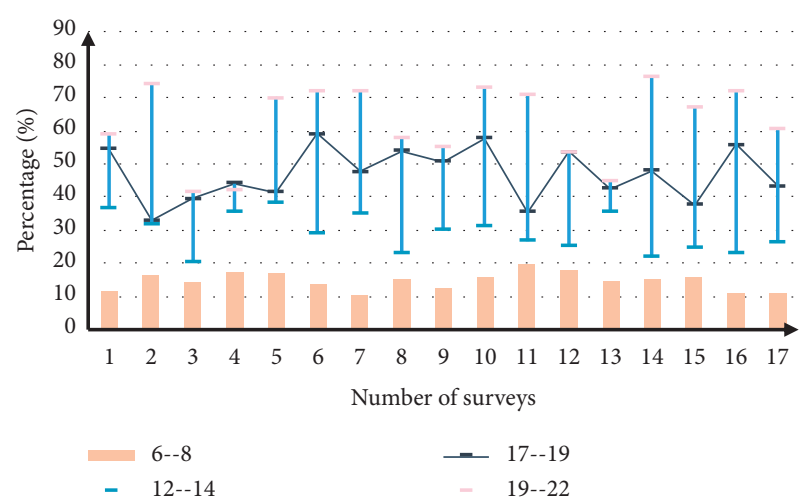

FIGURE 5: Opening hours of school sports resources.

and effective service to community sports is a problem that needs to be solved urgently.

The external service statistics of sports venue resources are shown in Figure 6. In some colleges and universities, the most external service time period for various sports venue resources is the two phases of weekends and winter and summer vacations, accounting for $37.3 \%$ and $29.1 \%$, respectively. During this period, venue resources serve community sports and do not affect the normal teaching order of colleges and universities. Holidays opening up is just in line with the principle of focusing on teaching, supplemented by external services, first inside out, and fulfilling the purpose of college sports resources serving community sports.

With the development of the concept of resource sharing, the state requires colleges and universities to build a new resource bond relationship between colleges and communities and serve the community while satisfying the utilization of colleges and universities, so as to promote the optimal use of resources. Facing the current dilemma in the development of community sports, colleges and universities should cater to the requirements of the country, change the old ideas, take into account the overall situation, and meet residents' expectations for the opening of college resources. In some colleges and universities, the service status of sports scientific research platform resources is not optimistic. According to the data, only $13.1 \%$ of them serve communities. For this reason, it is the most important task of the local government to break through the old view of college sports scientific research resources serving community sports. School sports resource sharing is shown in Table 6 .

Table 7 shows the participation of physical education teachers in sports activities outside school. The situation of participating in off-campus sports activities among school physical education teachers is as follows: only $28 \%$ of teachers participate in off-campus sports activities, $72 \%$ of teachers have not participated in off-campus sports activities, about $36.1 \%$ of students have participated, and about $63.9 \%$ have not participated, which indicates that college physical education teachers and students have a low awareness of participating in off-campus sports activities and failed to bring their sports professional knowledge into off-campus sports, but this is also a team with the potential to coordinate well between colleges and off-campus relationship which can not only input fitness guidance resources to outside the school but also bring a new 


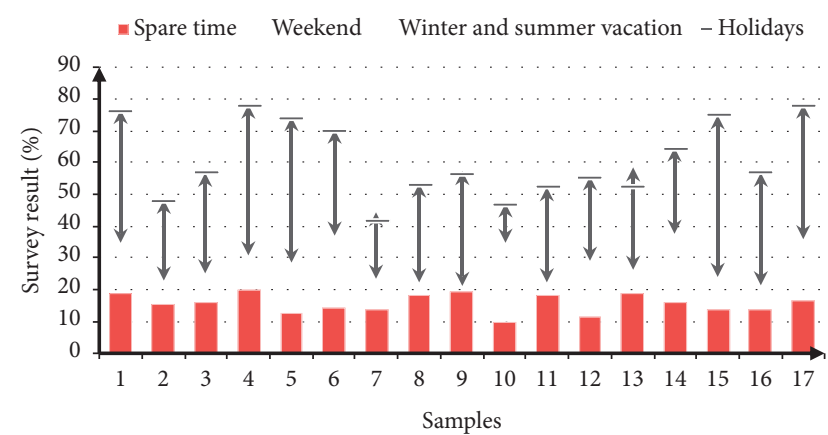

Figure 6: External service statistics of sports venue resources.

TABLE 6: School sports resource sharing.

\begin{tabular}{lc}
\hline Form & Percentage \\
\hline Service & 13.1 \\
No service & 86.9 \\
\hline
\end{tabular}

TABLE 7: Physical education teachers' participation in out-of-school sports activities.

\begin{tabular}{llcc}
\hline & Object & Participate & Not joining \\
\hline \multirow{2}{*}{ Teacher } & Number of people & 14 & 35 \\
& Percentage & 27 & 71 \\
\multirow{2}{*}{ Student } & Number of people & 65 & 118 \\
& Percentage & 31 & 64 \\
\hline
\end{tabular}

development platform for teachers and students to promote a mutual benefit for both parties.

The content of school physical education teachers participating in sports activities outside school is shown in Figure 7. The participation of physical education teachers in 5 schools in off-campus sports activities is mainly concentrated on competitions, the organization and planning of participating in events, and the opening of tutorial classes. The largest number is competitions and event planning, accounting for about $26 \%$ and $30 \%$. The development of collective projects requires a large number of participants, so a large number of executives are required; secondly, training courses are opened, accounting for about $20 \%$. Therefore, favorable conditions are provided for the establishment of various sports tutoring classes; about $12 \%$ are taught by outsiders, including lectures from other schools, training of referee levels, and training of fitness coaches outside the school. However, other aspects are not optimistic. For example, teachers and students participate in off-campus activities. This aspect is basically blank. In order to improve the national fitness program, schools and off-campus should strengthen exchanges and solve existing problems in order to give full play to the value of school sports resources.

\section{Conclusion}

This research mainly discusses the evaluation index system of school sports resources based on artificial intelligence and edge computing. Human resources, financial resources, and

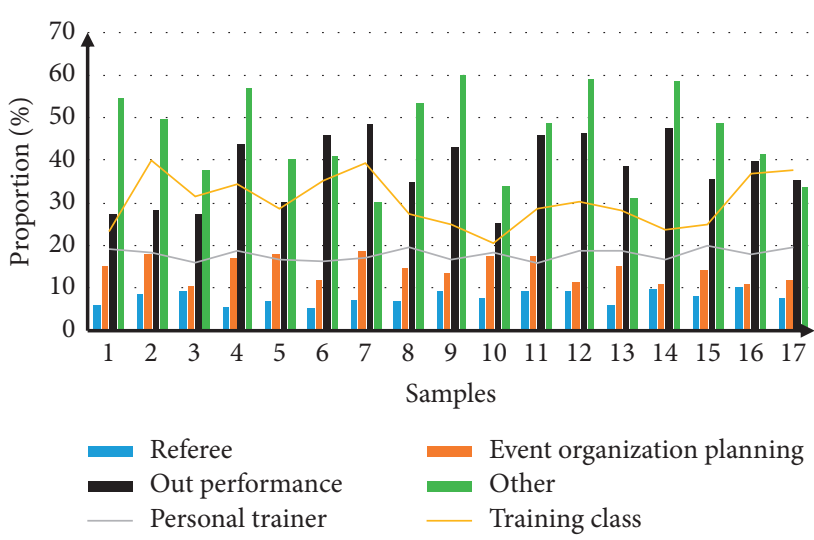

Figure 7: The content of school physical education teachers participating in sports activities outside school.

material resources in school sports resources are the three major resources in resource science. This research aims to establish a comprehensive platform for venue management information, collect multi-dimensional information, provide information resources, push accurate information, and link venue information with public fitness needs, and combined with artificial intelligence (AI) to create smart communities, smart venues, and realize an intelligent service system integrating important event venues, event services, intelligent operation and travel, and safety prevention and control. During the live broadcast of the student sports league, the nearby cloud processing of video data is realized in the form of edge computing, which improves the data computing ability and reduces the performance dependence on the user terminal equipment itself. In future research work, the competent government departments at all levels should play an active role in guiding and vigorously advocating the national sports open policy. Schools should actively create innovations based on their own school site resources and without affecting the safety of teaching and training. The conditions are open to the public, the society is the platform to meet the needs of bodybuilders, and reasonable opening hours and charging standards are formulated.

\section{Data Availability}

No data were used to support this study.

\section{Conflicts of Interest}

The authors declare that there are no conflicts of interest.

\section{References}

[1] Q. Xu, Z. Su, K. Zhang, and P. Li, "Intelligent cache pollution attacks detection for edge computing enabled mobile social networks," IEEE Transactions on Emerging Topics in Computational Intelligence, vol. 4, no. 3, pp. 241-252, 2020.

[2] Q. Luo, C. Li, T. H. Luan, and W. Shi, "EdgeVCD: intelligent algorithm-inspired content distribution in vehicular edge computing network," IEEE Internet of Things Journal, vol. 7, no. 6, pp. 5562-5579, 2020. 
[3] Y. Liu, C. Yang, L. Jiang, S. Xie, and Y. Zhang, "Intelligent edge computing for IoT-based energy management in smart cities," IEEE Network, vol. 33, no. 2, pp. 111-117, 2019.

[4] B. Cao, L. Zhang, Y. Li, D. Feng, and W. Cao, "Intelligent offloading in multi-access edge computing: a state-of-the-art review and framework," IEEE Communications Magazine, vol. 57 , no. 3, pp. 56-62, 2019.

[5] R. Dautov, S. Distefano, D. Bruneo et al., "Metropolitan intelligent surveillance systems for urban areas by harnessing IoT and edge computing paradigms," Software: Practice and Experience, vol. 48, no. 8, pp. 1475-1492, 2018.

[6] G. Jia, G. Han, H. Rao, and L. Shu, "Edge computing-based intelligent manhole cover management system for smart cities," IEEE Internet of Things Journal, vol. 5, no. 3, pp. 1648-1656, 2018.

[7] D. Sivaganesan, "Design and development ai-enabled edge computing for intelligent-IoT applications," Journal of Trends in Computer Science and Smart Technology, vol. 2019, no. 2, pp. 84-94, 2019.

[8] T. Wang, H. Luo, X. Zheng, and M. Xie, "Crowdsourcing mechanism for trust evaluation in CPCS based on intelligent mobile edge computing," ACM Transactions on Intelligent Systems and Technology, vol. 10, no. 6, pp. 1-19, 2019.

[9] M. Usman, A. Jolfaei, and M. A. Jan, "RaSEC: an intelligent framework for reliable and secure multilevel edge computing in industrial environments," IEEE Transactions on Industry Applications, vol. 56, no. 4, pp. 4543-4551, 2020.

[10] S. Chen, H. Wen, and J. Wu, "Radio frequency fingerprintbased intelligent mobile edge computing for internet of things authentication," Sensors, vol. 19, no. 16, pp. 12-15, 2018.

[11] J.-M. Hung, X. Li, J. Wu, and M.-F. Chang, "Challenges and trends inDeveloping nonvolatile memory-enabled computing chips for intelligent edge devices," IEEE Transactions on Electron Devices, vol. 67, no. 4, pp. 1444-1453, 2020.

[12] X. Wang, Y. Han, V. C. M. Leung, D. Niyato, X. Yan, and $\mathrm{X}$. Chen, "Convergence of edge computing and deep learning: a comprehensive survey," IEEE Communications Surveys \& Tutorials, vol. 22, no. 99, pp. 869-904, 2020.

[13] H. Lu, Y. Li, M. Chen, H. Kim, and S. Serikawa, "Brain intelligence: go beyond artificial intelligence," Mobile Networks and Applications, vol. 23, no. 7553, pp. 368-375, 2017.

[14] M. Jing, J. Yu, G. Hao et al., “Assessment of triglyceride and cholesterol in overweight people based on multiple linear regression and artificial intelligence model," Lipids in Health and Disease, vol. 16, no. 1, pp. 1-7, 2017.

[15] D. Hassabis, D. Kumaran, C. Summerfield, and M. Botvinick, "Neuroscience-inspired artificial intelligence," Neuron, vol. 95, no. 2, pp. 245-258, 2017.

[16] R. Li, Z. Zhao, X. Zhou et al., "Intelligent 5G: when cellular networks meet artificial intelligence," IEEE Wireless Communications, vol. 24, no. 5, pp. 175-183, 2017.

[17] J. H. Thrall, X. Li, Q. Li et al., "Artificial intelligence and machine learning in radiology: opportunities, challenges, pitfalls, and criteria for success," Journal of the American College of Radiology, vol. 15, no. 3, pp. 504-508, 2018.

[18] P. Glauner, J. A. Meira, P. Valtchev, R. State, and F. Bettinger, "The challenge of non-technical loss detection using artificial intelligence: a survey," International Journal of Computational Intelligence Systems, vol. 10, no. 1, pp. 760-775, 2017.

[19] T. Yang, A. A. Asanjan, E. Welles, X. Gao, S. Sorooshian, and $\mathrm{X}$. Liu, "Developing reservoir monthly inflow forecasts using artificial intelligence and climate phenomenon information," Water Resources Research, vol. 53, no. 4, pp. 2786-2812, 2017.
[20] M. Hutson, "Artificial intelligence faces reproducibility crisis," Science, vol. 359, no. 6377, pp. 725-726, 2018.

[21] C. Cath, S. Wachter, and B. Mittelstadt, "Artificial intelligence and the 'good society': he US, EU, and UK approach," Science and Engineering Ethics, vol. 24, no. 7625, pp. 1-24, 2017.

[22] M. Nasr, A. E. D. Mahmoud, M. Fawzy, and A. Radwan, "Artificial intelligence modeling of cadmium(II) biosorption using rice straw," Applied Water Science, vol. 7, no. 2, pp. 823-831, 2017.

[23] A. Agrawal, J. S. Gans, and A. Goldfarb, "What to expect from artificial intelligence," MIT Sloan Management Review, vol. 58, no. 3, pp. 23-26, 2017.

[24] E. Burton, J. Goldsmith, S. Koenig, B. Kuipers, N. Mattei, and T. Walsh, "Ethical considerations in artificial intelligence courses," AI Magazine, vol. 38, no. 2, pp. 22-34, 2017.

[25] J. Bryson and A. Winfield, "Standardizing ethical design for artificial intelligence and autonomous systems," Computer, vol. 50, no. 5, pp. 116-119, 2017. 